\title{
Con destino a una nueva comprensión de la fotografía posmoderna. La fotografía en su actuación social y otras intervenciones
}

\section{Artículo de reflexión}

\section{Juan Pablo Méndez Moreno}

Universidad La Salle Chihuahua, México

jpablomm@gmail.com

\section{Arturo Rico Bovio}

Universidad Autónoma de Chihuahua, México

aricobovio@hotmail.com

Recibido: 29 de abril de 2018

Aprobado: 14 de junio de 2018

Cómo citar este artículo: Méndez Moreno, Juan Pablo; Rico Bovio, Arturo (2019). Con destino a una nueva comprensión de la fotografía posmoderna. La fotografía en su actuación social y otras intervenciones. Calle 14: revista de investigación en el campo del arte 14(25), pp. 140-155. DOI: https://doi.org/10.14483/21450706.14055

\section{(c) (1)}

https://creativecommons.org/licenses/by/4.0/deed.es 


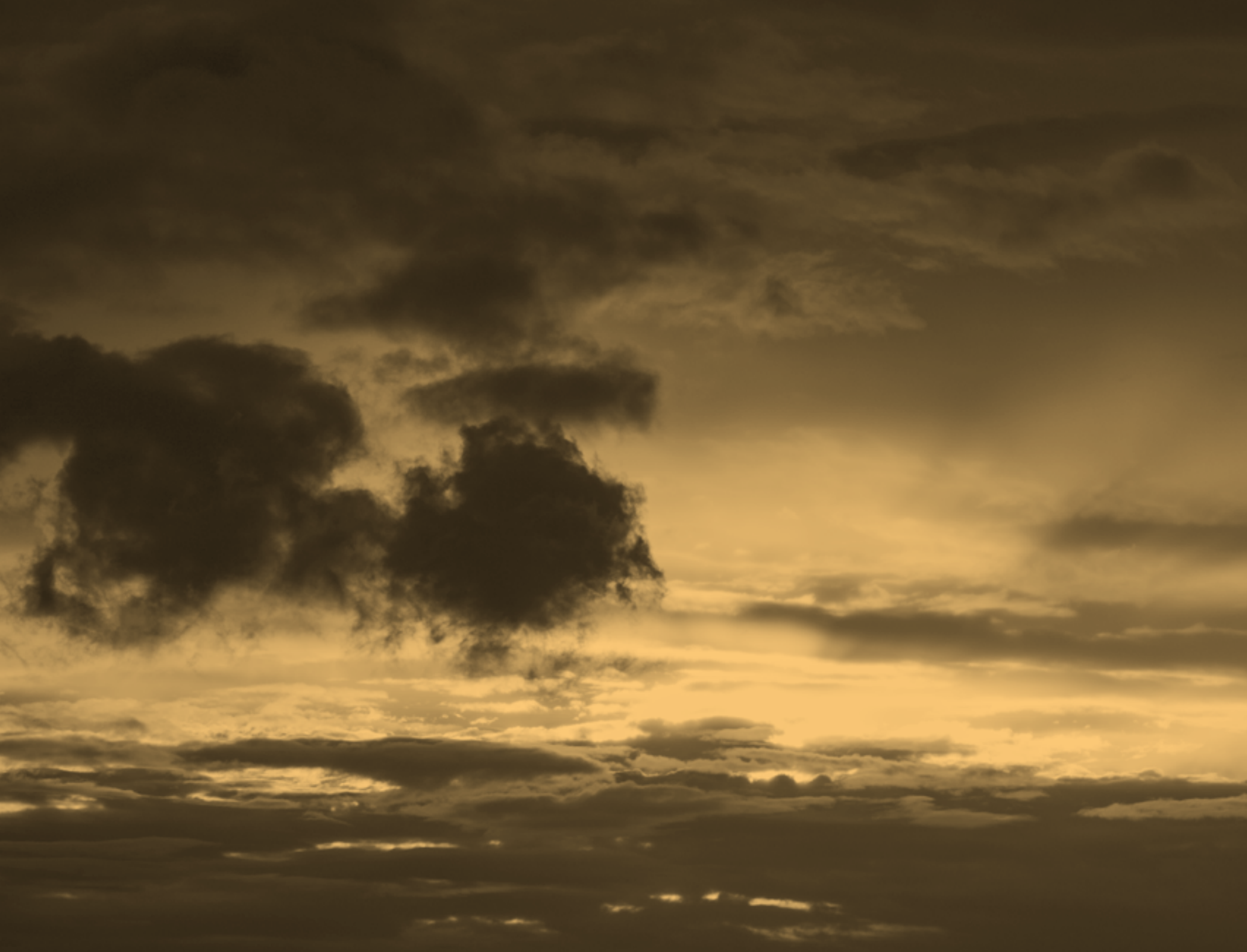


Con destino a una nueva comprensión de la fotografía posmoderna. La fotografía en su actuación

social y otras intervenciones

\title{
Resumen
}

Desde 1826 la fotografía ha sido un objeto de gran importancia para la sociedad. Tanto en su práctica como en su teoría ha aderezado todo lo concerniente a la historia de la humanidad. En el presente, la fotografía digital ocupa un lugar más prioritario que su antecesora, la fotografía análoga, debido a que se han multiplicado exponencialmente sus aplicaciones, funciones y capacidad. Por lo cual ahora hay que entender a la fotografía como un dispositivo de amplios espectro y radio, que contiene nuevas funciones, y que estas cambian nuestros pensamientos, conductas y visión de personas, lugares, objetos. Llegar a entenderla estaría más cerca por medio de la incursión de teorías, metodologías e hipótesis diferentes, lo cual permitiría establecer una nueva postura epistémica que nos permita aproximarnos al asunto de una manera holística.

\section{Palabras claves}

Dispositivo; fotografía; fotografía posmoderna; medios digitales; posfotografia

Towards a new understanding of postmodern photography. Photography in its social agency and other interventions

\begin{abstract}
Since 1826 photography has been an object of great importance for society. Both in its practice and theory it has touched everything concerning the history of humanity. In the present day, digital photography holds a higher priority and is more common place than its predecessor, analog photography, because its applications, functions and power have grown exponentially. Now we have to understand photography as a device with a broad spectrum and radio of action, which contains new functions that in turn change our thoughts, behaviors and our vision of people, places, objects. In order to understand it, the incursion of different theories, methodologies and hypotheses seems necessary, which would allow us to establish a new epistemic posture to tackle this subject in a holistic manner.
\end{abstract}

\section{Keywords}

Device; photography; postmodern photography; digital media; post-photo

Vers une nouvelle compréhension de la photographie postmoderne. La photographie dans son agence sociale et autres interventions

\section{Résumé}

Depuis 1826, la photographie est un objet de grande importance pour la société. Tant dans sa pratique que dans sa théorie, elle a touché tout ce qui concerne l'histoire de l'humanité. A I'heure actuelle, la photographie numérique occupe une place plus importante et prioritaire que la précédente, la photographie analogique, car ses applications, ses fonctions et sa puissance ont connu une croissance exponentielle. Nous devons donc maintenant comprendre la photographie comme un dispositif à large spectre et radio d'action, qui contient de nouvelles fonctions lesquelles, à leur tour, changent nos pensées, nos comportements et notre vision des gens, des lieux et des objets. Pour arriver à la comprendre, il semble nécessaire d'introduire différentes théories, méthodologies et hypothèses, ce qui nous permettrait d'établir une nouvelle posture épistémique pour aborder ce sujet de manière globale.

\section{Mots clés}

Dispositif ; photographie ; photographie postmoderne ; médias numériques ; post-photo 


\section{Resumo}

Desde 1826 a fotografia tem sido um objeto de grande importância para a sociedade. Tanto em sua prática quanto na teoria, tocou tudo o que diz respeito à história da humanidade. Nos dias atuais, a fotografia digital tem uma prioridade mais alta e é mais comum do que sua antecessora, a fotografia analógica, porque suas aplicações, funções e poder cresceram exponencialmente. Então, agora temos que entender a fotografia como um dispositivo com um amplo espectro e rádio de ação, que contém novas funções que, por sua vez, modificam nossos pensamentos, comportamentos e nossa visão de pessoas, lugares e objetos. Para compreendê-la, a incursão de diferentes teorias, metodologias e hipóteses parece necessária, o que nos permitiria estabelecer uma nova postura epistêmica para abordar esse assunto de maneira holística.

\section{Palavras-chaves}

Dispositivo; fotografia; fotografia pós-moderna; mídia digital; pós-foto

Ña Sugma allilla iuiarispa i intindirispa kai kawachiikuna kai punchakunamanda. Ña kai kaugsaipi pueblupi i imasami ka sug rimanakuikuna

\section{Maillallachiska}

Kai kawachiikuna kai wata waranga pusug pasa iskai sugta wata kaura iapa allimi karka. Kai tsabaju karkasi imasa allí ruraska i allí kilkaska i pairrinimi imasami parlu karka Nukanchipa runakunapa i pairrinimi imasami parlu karka Nukanchipa runakunapa kaugsai kaura. Kai kawachipika ikuti kami iuiaringapa i kai tsabajukuna kunga kai kawankuna chasaiatatami rimai tia wairaiapi i kai iukami musu iachaikuikuna kai tsukami Nukanchipa iuiai i imasami kaugsanchi kai alpakunapi, kai Tukui atun alpapi. Kai ña suma intindigapa chaiakumi kawachinga sug luarkunapi mana ñima iachagkunata.

\section{Rimangapa Ministidukuna}

Ima rurangapa kagta; kawachingapa; kawachingapa kai punchakuna; ña sug musuglla iachaikungapa kilkaspa; ñugpa kawachingapa 


\section{Para entender el dispositivo "fotografía"}

La palabra "dispositivo" contiene una sumatoria de reflexiones elaboradas durante muchos años de filosofía, que le han permitido asumir un papel clave en cualquier investigación. Adoptarla exige una previa justificación, por tratarse de un término estratégico del pensamiento de Foucault (Agamben, 2006, p. 35). En este trabajo no se trata de llegar a una propuesta alternativa o un cambio filosófico de la definición o uso del término, sino de aplicarlo con un enfoque personal que permita un mejor entendimiento de la fotografía, pues el interés de la investigación radica en la hipótesis de que la fotografía establece un punto de intersección de lo antropológico, lo sociológico, lo histórico, lo artístico y lo filosófico y por consecuencia puede ser perfectamente designada como un "dispositivo".

Revisemos la definición de Agamben de la palabra "dispositivo", para justificar nuestra opinión de que es la más asertiva para acercarse a la fotografía, a fin de analizarla y definirla conforme a la postura integral que se pretende manejar sobre la fotografía. Señala Agamben: "llamaré dispositivo literalmente a cualquier cosa que de algún modo tenga la capacidad de capturar, orientar, determinar, interceptar, modelar, controlar y asegurar los gestos, las conductas, las opiniones y los discursos de los seres vivientes" (Agamben, 2006, p. 23). Esta definición se ajusta en todas sus características a la fotografía, hecho que permite redefinirla como dispositivo, pues cumple y acciona cada una de las notas conceptuales enunciadas.

La captura de la luz en la fotografía es uno de los modos en que se puede manifestar como dispositivo, pues "capturar" es también una apropiación y la fotografía aprisiona no solamente la luz de acuerdo a su mecánica, sino en el mensaje, su simbolismo, la iconicidad y la ontología de aquello que se muestra frente a ella; se trata del significado de aquello que el hacedor de fotos se ha dispuesto a sujetar y posteriormente tocará al lector leer. La fotografía pone en cautiverio todo aquello que se le comande, tras apresar todo lo evidenciado por la luz. Así, la fotografía manifiesta su poder de captura y precisamente en este sentido cabe la enunciación: "Fotografiar es apropiarse de lo fotografiado. Significa establecer con el mundo una relación determinada que parece conocimiento, y por lo tanto poder" (Sontag, 2016). Es posible capturar todo aquello que establece una liga de conexión con cualquier asunto de la vida humana.
La fotografía de ahora se ha vuelto la secuestradora del apunte, de la libreta de tareas, del espejo para maquillarse. Es el testigo ocular en accidentes o crímenes, la representación onírica, la expresión artística, el lenguaje universal, la ciencia en introyección a los cuerpos, el vigilante ciudadano, el oficial de tránsito, el escáner, la fotocopia, la vigilancia en casa, el recuerdo de la felicidad de un evento familiar y mucho más.

Antes la cámara capturaba en el negativo, en las películas de acetato o en un positivo directo a través de la técnica de grabado "daguerriana" en una placa de plata. Ahora las cámaras digitales cuentan con la capacidad de capturar de igual modo la luz, y en cualquiera de los dos casos (análogo o digital), siguen siendo un dispositivo de captura. Por su naturaleza y herencia, no importa a qué tipo de aparato se refiera, ya sea una película de acetato o un sensor o incluso una caja oscura con haluros de plata en un soporte, mientras cumpla la función de grabar la luz es fotografía.

Marvin, en su libro Photography Changes Everything, nos permite entender que la fotografía, desde su industrialización y comercialización con equipos portátiles y de fácil acceso, ha suscitado y provocado que prácticamente cualquier disciplina y acción humana se subordine a ella (Heiferman, 2012, pp. 15-16), al hecho de ser registrada y evidenciada, desde las artes, la ciencia o la religión, hasta la más vacua de las actividades humanas y eso lo cambia todo, puesto que en alguna forma la fotografía también captura nuestro pensamiento, pues no existe el hecho si no es fotografiado. Es muy significativo que nuestra confianza en la creencia de que haya sucedido algo radica en que se nos muestre la imagen, video o foto y, por consecuencia, la asertividad y realidad de los eventos es precisamente secuestrada por el dispositivo fotografía, lo que permite la regresión a la parte ontológica ${ }^{1}$ de la foto. Añadamos a lo anterior unas palabras que permiten resumir el esquema de lo anterior: "fotografío, luego existo" lo cual nos convierte en homo photographicus (Fontcuberta, 2016).

El dispositivo fotografía captura y encarcela al mundo, lo va aprisionando, construyendo y reconstruyendo una y otra vez, en su almacén virtual y físico, ahí en donde hemos dejado que las imágenes reposen. El mundo

1 Entendiendo a la ontología como la procedencia de la realidad tangible: "La imagen puede ser borrosa, estar deformada, descolorida, no tener valor documental; sin embargo, procede siempre por su génesis de la ontología del modelo. De ahí el encanto de las fotografías familiares" (Bazin, 1976). 


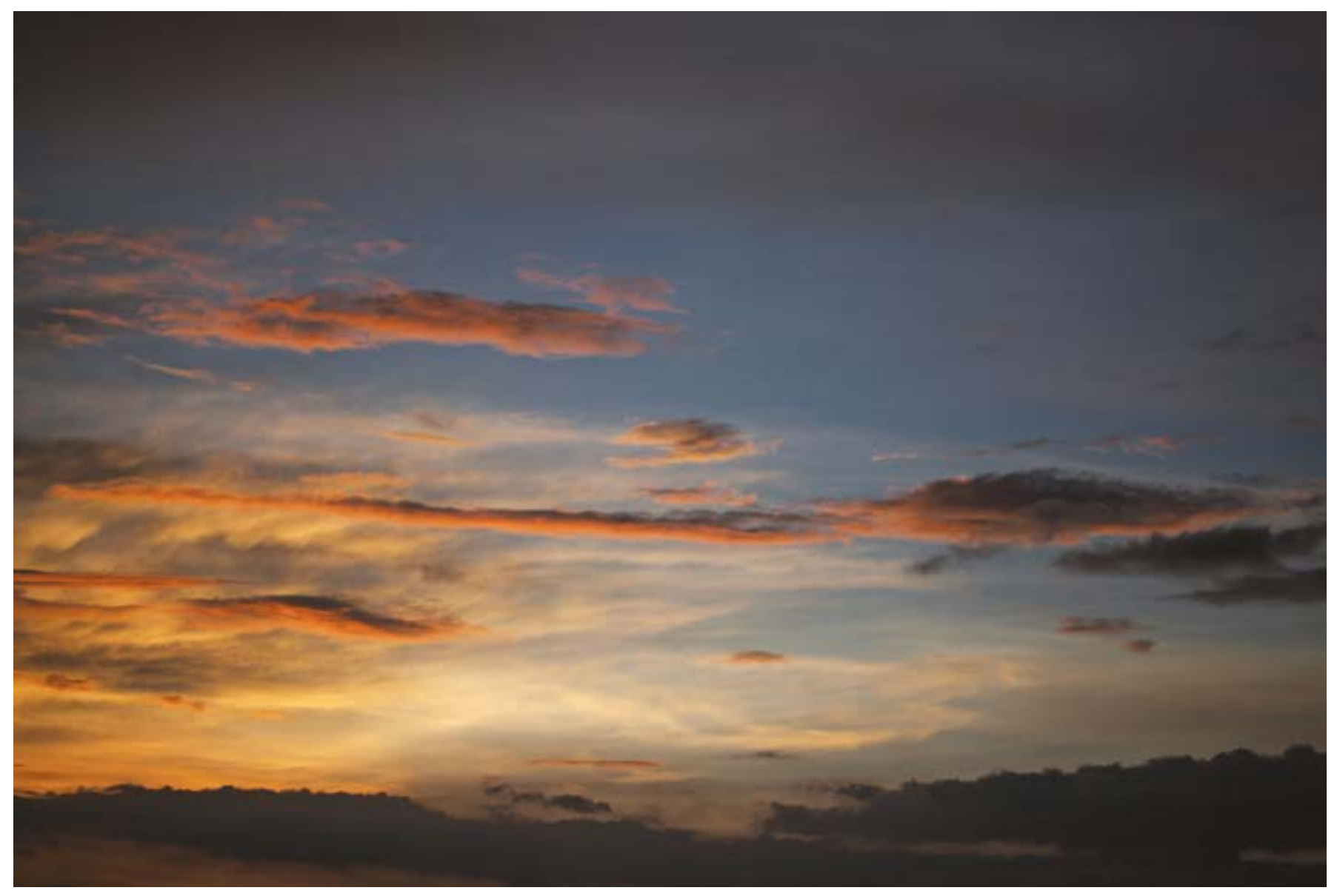

Imagen 1. 19/11/13. Sandra Rengifo. De la serie: Pil På Himlen (Flecha en el cielo). 2012 -2015. Fotografía Digital.

es fotografiado en cada espacio, cada rincón y ello va permitiendo crear un mundo paralelo que posibilita cada vez más la probabilidad de habitar en él. El mundo se contiene ahora en la fotografía, se conoce a través de ella y eso no es más que el secuestro del mundo por la misma.

La fotografía tiene en su forma nata la habilidad de capturar no solo el evento congelado que se muestra, sino el hecho, la historia, la escena; esto la proyecta con más poder, al capturar no solo el paso de luz sino nuestra memoria, pues repasamos una y otra vez las imágenes para imaginar (Flusser, 2010, p. 14).

Pensemos en la fotografía como la máquina que captura, que plasma o posterga aquello que por la luz ha sido fijado. Por definirla de otra manera sería “...un recuerdo de una vida que está siendo vivida" (Berger, 2013): en relación con esta frase de Berger habría que pensar también en que la fotografía muestra la vida que ya no es vida sino, en términos derridianos, el "fantasma" (1995) de ella. Dubois, por el contrario, aumenta las definiciones sobre este dispositivo, que van más allá de una concepción de ecuación simple. Para Dubois existen tres grandes concepciones de la fotografía, que guardan una estrecha relación con la mitología griega. La primera de ellas es la fotografía como "espejo" de lo real, la segunda como "transformación" de lo real y la tercera y última como "huella" de lo real.

Dentro de esta concepción se manifiestan una serie de análisis y conclusiones del autor sobre la fotografía y su modo de actuación sobre la sociedad o el lector. Lo que hace falta es precisar dentro de las tesis del autor la utilización y definición de la palabra realidad; parece que a lo largo de su trabajo, implícitamente, supone la idea de que la realidad es aquello que se encuentra físicamente, lo que le permite a lo largo de su trabajo exponer esta parte ontológica plasmada en la fotografía; interpretación con la que concordamos sólo parcialmente, pues habrá que trasladar esas reflexiones a diversos terrenos, entre ellos la realidad virtual que presentan en la última década las TIC (Tecnologías de la Información y la Comunicación).

Habrá que contemplar a la fotografía en sí como un dispositivo de captura de la luz de forma genérica, puesto 
a la orden de quien lo comande, incluyendo todo aquel aparato que grabe a través de la luz una imagen sobre un soporte, sin importar la lente, marca o técnica con la que se realiza. La fotografía habrá que ser entendida como el elemento genérico, lo que formula un mensaje y una categoría, aquello que sirve a todos sus amos y que está dispuesta a ser el soporte de cualquier tipo de código que pueda ser heliograbado.

El capturar también es coleccionar; nos hemos vuelto coleccionistas de imágenes, poseedores de fotografías, como si eso fuese lo que nos da fe de una estancia terrenal, de una vida vivida. Generamos y consumimos sin descanso, sin prohibiciones, sin límites, solo: “Produciendo imágenes (capturando posesiones) la persona se realiza dentro de la sociedad burguesa y se prepara para su etapa de consumidor de imágenes" (Echevarren, 2010, p. 5). Coleccionar fotografías es un acto de sustitución, de dominio y control sobre las cosas y posiblemente también sobre las personas.

Desde un enfoque psicológico, el coleccionista tiene una cierta motivación por recolectar, y dicha motivación se conecta con las necesidades del individuo: "La colección no es solamente un conjunto más o menos ordenado de objetos, es principalmente, una forma de pensar y concebir relaciones significativas entre objetos y de éstos con el 'mundo' o el contexto social al cual pertenecen" (Costa, 2007, p. 813). El fotógrafo va coleccionando en el momento en el que convierte a un 'algo' en un objeto, en una emoción, en un recuerdo y eso lo hace un elemento coleccionable. En realidad a todo lo que se fotografía lo convertimos en una pieza, en un trofeo. Un coleccionador cuida su tesoro, porque cada uno de ellos representa un valor subjetivo interpretado, principalmente, por el mismo coleccionador. De igual manera la fotografía, cada una, se convierte en un significado especial. Baudrillard comenta: “...el objeto puro, desprovisto de función o abstraído de su uso, cobra un status estrictamente subjetivo. Se convierte en objeto de colección" (1981).

Por otro lado, la capacidad del dispositivo en su labor de orientar, le viene inscrita en su código. Pensemos en la ciencia que realiza investigación para lograr nuevos avances en materia de la creación de cámaras fotográficas más compactas, mejores, más ligeras, o para colocarse en un dron, en unos lentes, en una pluma, en un reloj, en un muñeco de peluche, en los timbres de casa, suplantando la función de un botón en la indumentaria; incluso tan grandes que captan imágenes de alta calidad desde el espacio insertadas en un satélite, así como desde la tierra también fotografían al universo que nos rodea.

Los avances tecnológicos de la ciencia permiten que tengamos cámaras para todo lo que se nos ocurra ver y escudriñar, como la cámara fotográfica que se adhiere a microscopios para obtener muestras visuales y con ello orientar los resultados bajo las indiscutibles pruebas que ofrece la fotografía, o bien en un robot que permita a los equipos especiales de la policía ver un lugar en su interior, o en un casco de protección de los militares al ejecutar una misión, mientras los políticos o altos mandos de los cuerpos de la ley observan el acto como en una película.

“La originalidad de la fotografía con relación a la pintura, reside por tanto en su esencial objetividad. Tanto es así, que el conjunto de lentes que en la cámara sustituye al ojo humano recibe precisamente el nombre de objetivo"(Bazin, 1976, p. 35). En un intento de complementar la idea del autor, nos parece más bien que la fotografía ha permitido ampliar nuestra mirada, no sustituirla, llegar más lejos de lo que hemos podido llegar con nuestra vista natural; esa prótesis visual con la que ahora contamos, ese tercer ojo, se ha convertido en atlas para movernos en el mundo, para interactuar con él y para conocerlo.

\section{El control de la ideología social a través de la fotografía}

En camino de estas mismas ideas, Errol Morris se encarga de mostrar cómo las fotografías son instrumentos que orientan los pensamientos sociales y alimentan los debates entre intelectuales. En su tesis Believing is Seeing: Observation on the Mysteries of Photography, va denunciando como se construyen tanto las fotografías como las noticias que surgen de ellas y, principalmente, la creencia que se forma partiendo de las fotografías expuestas de manera masiva en cualquiera de los medios de comunicación disponibles.

En uno de sus ejemplos utiliza la fotografía de "Valley of the Shadow of Death", tomada por el fotógrafo, Roger Fenton en 1855 en la guerra de Crimea y coloca como centro de atención las sentencias que emite Susan Sontag en su libro Regarding of the pain of Others, sobre las fotografías de Fenton, a lo cual Morris argumenta que es sumamente complicado entender si una fotografía fue alterada o no en su contenido escénico, para juzgarla de una manera o de otra (Morris, 2014, 
p. 3) o decir si es verdadera o no. Lo importante sobre estas premisas de verdad, es que el dispositivo fotografía orienta cuestiones políticas y académicas, crea debates y formula hipótesis de acuerdo a los hechos y a la interpretación que una investigación arroje; paradójicamente en estas investigaciones se utilizan otras fotografías para llegar a la verdad sobre una cierta fotografía.

Así mismo hay que mencionar que la ciencia, en aras de las nuevas tecnologías para la toma fotográfica, orienta a la sociedad hacia una forma de captura fotográfica, pero esta evolución exige y reinventa a su vez a la cámara fotográfica, tanto en su uso como en su aplicación y por ende al fotógrafo, al fotografiado y lo fotografiado. Habría que observar y analizar esas nuevas fotografías que circulan en todos los sitios, pues ahora contienen códigos binarios inscritos en sus metadatos que activan la hipertextualidad y otras acciones de código informático, actividades que involucran el tener una interacción con la fotografía, ya sea agrandando la imagen, rotándola en $360^{\circ}$, conectando con otras redes sociales o sitios web, entre otras. En realidad, la fotografía ha cambiado dramáticamente en su naturaleza; aunque se mantenga la genética inicial, ahora la foto es un dispositivo de orientación de acciones.

Otro rasgo de la ciencia aplicada a la fotografía es que orienta a la reinvención de la cámara nuevamente. Éste fenómeno es un acto retro-alimentativo de la ciencia, marinada por el hambre del consumo social, la industrialización, la tecnología y los hábitos de dispendio de imágenes que en nuestros días sustentan una cosmovisión de lo que fuimos y lo que somos, a donde hemos llegado y hacia dónde vamos. Además, hay que dejar en claro que este mismo dispositivo orienta al hiperconsumo de imágenes, pues entre más fotos encontramos en los sitios, más fácil es que los lugares sean representados por las imágenes y no al revés.

El dispositivo fotografía determina los diálogos llevados a cabo entre los individuos al ver una foto, enfoca el pensamiento del lector en su mensaje, orienta y captura la imaginación, la interpretación, y con ello decreta el marco que delimitará la periferia del diálogo venidero, incluso de la interlocución o del monólogo.

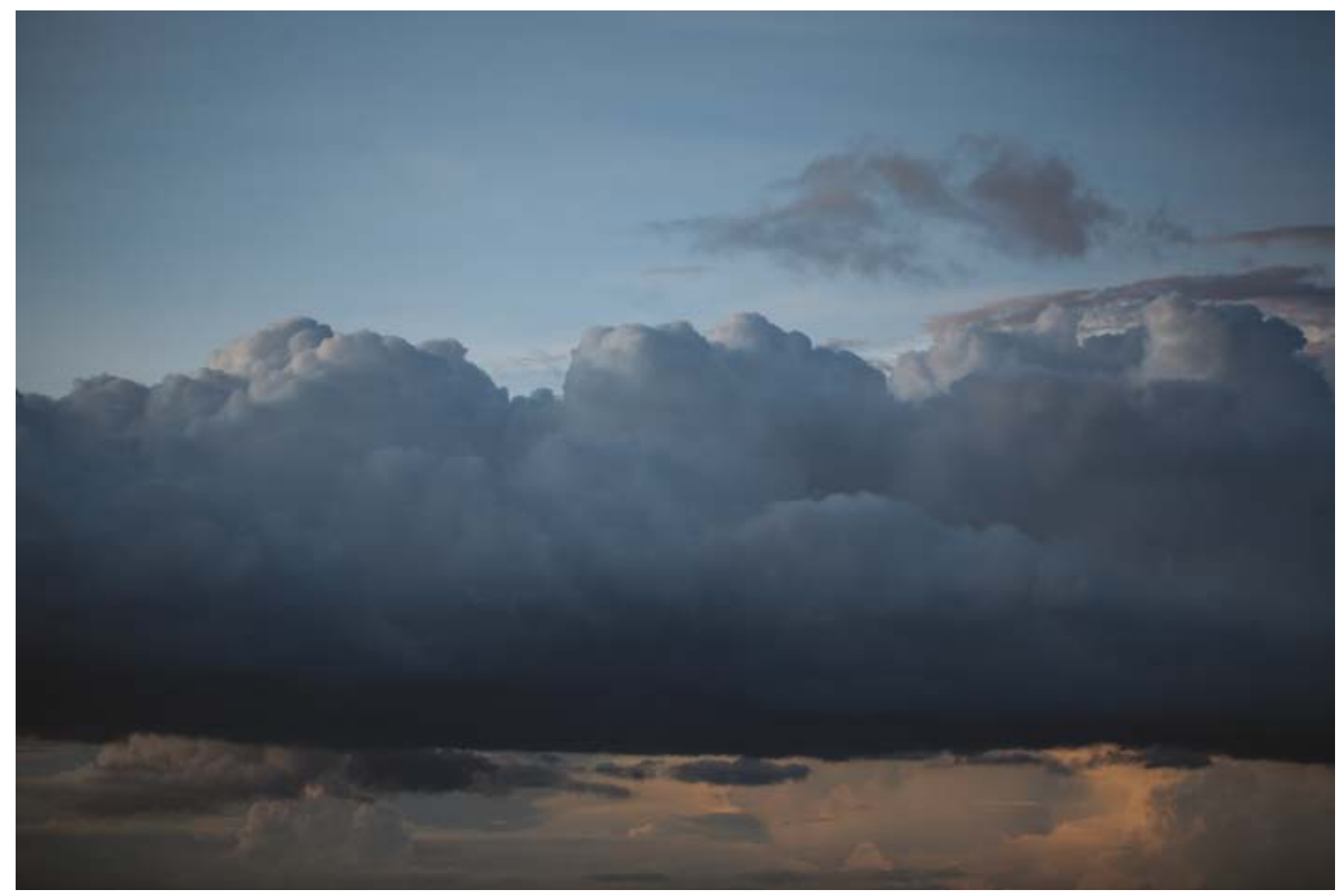

Imagen 2. 12/11/13. Sandra Rengifo. De la serie: Pil På Himlen (Flecha en el cielo). 2012 -2015. Fotografía Digital. 


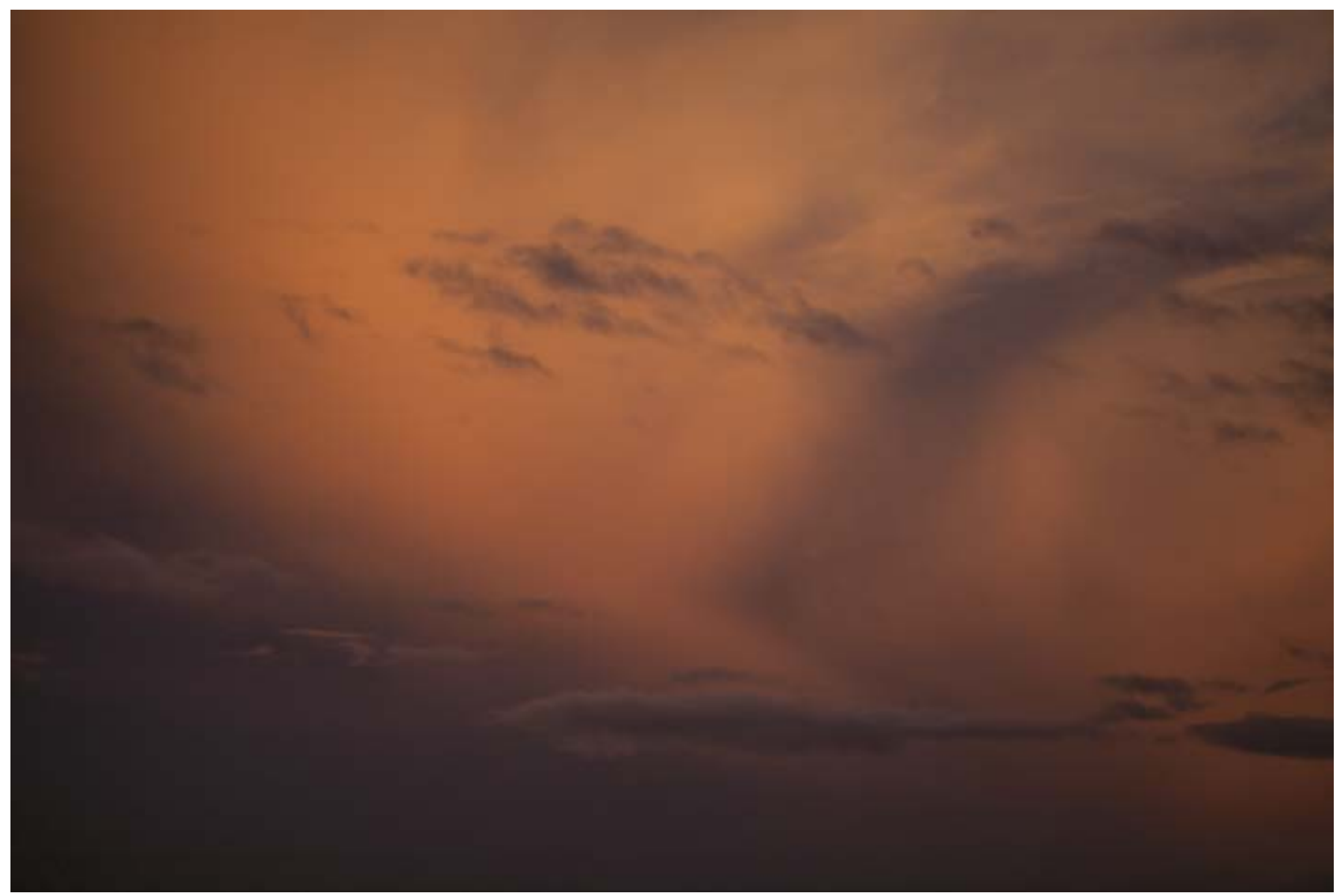

Imagen 3. 23/08/13. Sandra Rengifo. De la serie: Pil På Himlen (Flecha en el cielo). 2012 -2015. Fotografía Digital.

Cada fotografía es una manera de entablar una comunicación y de limitarla, pues sólo se puede hablar de esa imagen en sí misma, aunque su periferia sea amplia y el contexto una red de teorías y pensamientos; la foto determina cuál será el tema de conversación.

El diálogo determinado por la fotografía puede extender su horizonte tanto como se le indique, desde conversaciones vanas y frívolas, hasta reflexiones filosóficas de gran envergadura. No obstante, se podría mencionar que existe una zona gris en el diálogo fotográfico, la zona neutra de la determinación dialógica fotográfica es ella en sí misma, pues no se pide nada, solo permite que su mismo creador, lector, visor o analista, la lleve al cauce que le parezca mejor; es ahí en donde la foto puede ser perteneciente a cualquiera de las categorías dialécticas determinadas por la imagen misma. La fotografía no puede pretender conocer de antemano o controlar el alcance del diálogo que ella genere, pero sí determina su contexto.

El diálogo sí puede estar, de alguna manera, determinado por el espacio físico, aunque puede interferir directamente con el sitio y la forma en la que se lleva a cabo. Cada lugar pretende ser un recinto para la fotografía; la imagen fotográfica es la reina de las imágenes. Es tan importante para la sociedad que se asignan espacios públicos exclusivos y de altura para colocar cada fotografía, ya sea en los sitios supuestamente asépticos llamados museos, el transporte colectivo, un edificio, una plaza comercial o bien un espectáculo. Incluso en el ordenador o en un celular se le llega a dar un lugar especial al colocarla como fondo de pantalla. Hasta nos permitimos que nuestra foto sea colocada en nuestro perfil de las redes sociales y accedemos a otros cientos de miles de millones de imágenes, para definir un estado de ánimo o tomamos fotografías de los lugares a los que vamos. Pareciera que el sitio ya no fuera lo que importa sino la fotografía que obtenemos de él, para tener una posición social o simplemente mostrarla. La experiencia es sustituida por el acto fotográfico; pareciera que representa más una fotografía del evento o el acto vivido que estar consciente del presente que se experimenta: "La mayoría de los turistas se sienten obligados a poner la cámara entre ellos y toda cosa destacable que les sale 
al paso. Al no saber cómo reaccionar, hacen una foto. Así la experiencia cobra forma" (Sontag).

El dispositivo fotografía, a causa de estos intentos de supervivencia cibernética, determina la reproductibilidad del sitio, del hecho, del objeto y de las personas. Ahora nos multiplicamos y estamos repartidos en diversos sitios al mismo tiempo. Jamás se había visto tal caso de omnipresencia y teletransportación de las personas y las cosas. No se nos ocurre nada que no esté fotografiado; hasta lo más ignominioso recorre los espacios cibernéticos. La fotografía determina la reproducción a causa de su natividad binaria y aunque la multiplicidad ya se presentaba con la imagen análoga, en el presente evoluciona y se propaga con mucha más facilidad. En este sentido los comentarios: "...la instalación Photography in Abundance de Erik Kessles... 2011 en el museo FOAM de Ámsterdam... La instalación consiste en el mero volcado de cerca de un millón y medio de fotos, descargadas de internet e impresas a tamaño tarjeta postal... Esa enormidad correspondería a la cantidad de archivos subidos al portal Flickr durante un período de 24 horas" (Fontcuberta, 2016). "En otro nivel más psicológico, la foto es una defensa contra la ansiedad. Fotografiar proporciona una ilusión de poder sobre objetos y personas, e incluso poder sobre el tiempo y el espacio" (Echevarren, 2010, p. 45).

Consideremos ahora la manera como la fotografía determina la postura del cuerpo en la interacción del ser humano con ella al momento de ser leída o interpretada: nos hace voltear a una determinada zona y/o altura para ver lo observado. La fotografía, situada en el espacio físico público, es un elemento al que hemos asignado un gran valor, la enaltecemos tanto que la agigantamos, la adoramos, la hacemos espectacular y le damos un lugar privilegiado en la construcción arquitectónica. Se hacen armazones que sirven como marco para colocar fotografías, se cubren caras de los edificios, se colocan pantallas gigantes en las avenidas, fachadas y paredes de nuestro hogar; mientras levantamos la mirada para verlas.

Este tipo de acciones físicas que se llevan a cabo con el cuerpo, denotan un simbolismo muy semejante al celestial, pues tratamos a las imágenes con idolatría, casi como si de magia se tratara; parecieran una especie de tótems a los cuales rendimos culto. Posiblemente hemos llegado al punto en el que enaltecemos tanto a la fotografía que se ha convertido en lo absoluto, en el todo, lo representado y por representar. Pero por contraste es lo efímero, lo volátil, pues las fotografías son rápidamente suplantadas por otras. Las fotografías son celosas y el devenir maquilero de las imágenes que ahora presenciamos se ha convertido en el pulso del mundo y en la representación histórica y presente de sus habitantes.

Hoy por hoy la evolución de este fenómeno que data de los 90's, se ha trasformado en lo que se llama postfotografía. Este término todavía no acaba por definirse; aunque teóricos como Fontcuberta, señalan a la postfotografía como la segunda revolución digital, en la cual la fotografía nos habita y nosotros habitamos la imagen y ésta sostiene una nueva realidad fabricada por ella (Fontcuberta, 2016). Por otro lado J. L. Caivano define a la postfotografía como la fotografía que no es fotografía, pues no utiliza la técnica tradicional con un objetivo y un sensor digital que capte la imagen; incluso la denomina "pos-fotografía", alterando un poco la palabra que comúnmente se utiliza (1999, p. 40). Göran Sonesson, al igual que Caivano, define principalmente a la postfotografía como el realizar imágenes a través del ordenador, sin incluir un aparato fotográfico como tal, aunque sí incluye fotografías de la web y creaciones gráficas (vectores), para posteriormente alterarlas en su originalidad, provocando un mensaje distinto, al que también ha llamado por semejanza el net-art o hacktivismo (Sedano 2015, p. 132).

La metafotografía a la que hemos llegado (si es posible llamarla así), es más inteligente que cualquier otra de sus antecesoras, pues ahora la imagen guarda e intercepta no solamente códigos embebidos dentro de ella, sino textos o hiperlinks y evoluciona a formatos de vistas en $360^{\circ}$, fotografías holográficas, térmicas, infrarrojas, ultravioletas, técnica de kirilian, ortofotografía, foto estereoscópica, entre otros. Aunado a ello se utilizan intervenciones y alteraciones gráficas, en ocasiones físicas, otras a través de un programa o aplicación para edición. Esto otorga a la fotografía nuevos significados, pues cada fotografía puede ser editada en su contenido infinitamente. Ahora no solo cambian las formas de hacer las técnicas fotográficas para ver de manera distinta, sino también las mismas cámaras; los celulares incorporan cámaras de doble lente que le brindan nuevas funciones (profundidad de campo) y posiblemente se retomen las cámaras análogas de cuatro lentes que se utilizaban para fotografía de identificación y sean ahora empleadas para ver las cosas de cuatro modos distintos al mismo tiempo o produzcan efectos o funciones completamente distintas a las que hoy conocemos. Una alteración más a nuestro modo de ver. 
Las fotografías forman el nuevo atlas del mundo, crean y determinan un mapa cibernético interceptando lo físico; es una construcción de lo conocido a base de fragmentos y abstracciones (encuadres), alejamientos y acercamientos de las cosas; ${ }^{2}$ una cartografía visual de todo lo relacionado con la humanidad, su presente y su historia, así como de la naturaleza. Este atlas cibernético tiene el poder de separar al mundo virtual de lo físico y convertirlo en la referencia de las cosas tangibles; el Google Street View es una prueba precisa. Ahora viajar para conocer al mundo es posible también acudiendo a dispositivos informáticos con acceso a Internet y con herramientas como Google Earth; también permite observar ese mundo virtual al mismo tiempo que el físico a través de un aparato tecnológico.

La fotografía, en su ejercicio de mapeo, funciona a través de múltiples factores: percepción, ángulo de visión, lugar y tiempo; ${ }^{3}$ cada uno de ellos definido por el hacedor de fotos, quien delimita (encuadra) al "objeto fotografiado". Al fotografiarlo proporciona una respuesta plástica de la cosa que se convierte en una pluralidad, pues las cosas son ahora continuamente sobrefotografiadas. Entre todas las fotografías del mismo objeto, a pesar de pertenecer diferencialmente a cada uno de los múltiples factores que le dieron origen (principalmente el del tiempo), se convierten en una percepción individual del objeto fotografiado, ofreciendo por su interpretación un ángulo diferente, siendo cada imagen una referencia a las fotografías que en distintos lugar y tiempo ya existen de él, convirtiéndolo así en una de pluralidad de sí mismo.

Como consecuencia de cada cosa se obtienen distintos ángulos de visión que dan forma y volumen a las cosas de este atlas cibernético ${ }^{4}$ dando estructura y sentido a todo nuestro universo visual. Cada foto nueva se encima a la anterior y cada cosa fotografiada se altera constantemente por su forma de verlo. Belting lo comenta diciendo que cada espacio ahora conocido es a partir

2 Utilizaremos la palabra cosa(s) en este apartado como sinónimo o suplantación de las palabras: objetos, lugares y personas; esto sin caer en la idea de cosificación, sino solamente por su practicidad en la escritura y la lectura.

3 Los múltiples factores serian analógicamente parecidos (no iguales) a las modalidades que comenta Dubois, que son: circulación, intercambio y arrancamiento. El contraste es la referencia a los múltiples factores como agentes de un proceso morfológico del mapeo realizado por la fotografía.

4 Defino atlas cibernético como los sitios de almacenamiento de las fotografías virtuales que dan forma a un mundo construido por imágenes y en donde estas imágenes se traslapan una y otra vez. de la imagen a la que podemos acceder: “(...) es posible hablar de lugares geográficos a los que las obras en imágenes establecidas allí otorgaron el rostro que se conoce" (Belting, 2007, pp. 76-77). Debido al aumento de fotografías que existen de las cosas, ahora podemos acceder a colecciones innumerables de imágenes de cada una de las cosas que se encuentran en el mundo.

Este atlas cibernético al que accedemos constantemente y que se ha convertido en nuestra primera referencia visual de las cosas es también, como lo comenta Dahó en relación a la teoría de Azoulay: un espacio de interacción de todos en donde cada uno ejerce libertad y poder, lo que permite que cada fotografía sea una concepción del espacio público, una forma de estar con los demás (Dahó 2015, p. 229), pues cada uno de nosotros se conecta con las fotografías que están en la representación de un algo ${ }^{5}$ y acabamos siendo fotografía. Román Gubern explica que este ciberespacio es una realidad virtual $-\mathrm{RV}-\mathrm{y}$ que puede ser definida como “(...) un sistema informático que genera entornos sintéticos en tiempo real y que se erigen en una realidad ilusoria (...) pues se trata de una realidad perceptiva sin soporte objetivo, sin res extensa, ya que existe sólo dentro del ordenador" (Gubern, 1996). Con respecto a lo dicho por Gubern, ahora los ordenadores ya no son los únicos contendores y conectores a esa RV; actualmente los dispositivos con conectividad a Internet se multiplican en diferentes clases, se diversifican a tal grado que estamos en una era del Internet de las cosas, los electrodomésticos, las luces, las persianas, las chimeneas, los aparatos de música, las televisiones, las cámaras de seguridad ${ }^{6}$, son controlados por medio de Internet y los soportes de almacenamiento se diversifican y aparece la nube (cloud ${ }^{7}$ ) permitiendo que las fotografías se alberguen en discos duros de libre acceso las veinticuatro horas los trescientos sesenta y cinco días del año.

5 Menciono la palabra "algo" en sustitución de: eventos, perso-
nas, lugares, cosas, entre otros.
$6 \quad$ Es importante analizar el fenómeno de la extensión de la
vista que se ejerce por medio de los dispositivos, pues estando en
cualquier lugar del mundo con conexión a Internet, se puede dividir
nuestra mirada tantas veces como el número de cámaras con el
que contemos, y así tener presencia óptica en todos esos sitios; si
cuentan con el mecanismo adecuado, nuestros ojos electrónicos
se pueden mover, acercarse o alejarse a voluntad de unos "gestos
manuales" realizados en una pantalla y controlados por el disposi-
tivo (celular o Tablet). Más adelante lo abordaremos como la visión
posmodernista.
$7 \quad$ Servicio para usuarios independientes o empresas de almace-
namiento de archivos en internet por medio de servidores.


Cada fotografía almacenada en los discos duros es un código binario que, en teoría, es único e irrepetible, es lo que le da su "genética". Pero en la fotografía digital esa genética binaria se multiplica y es controlada con facilidad para su reproducción o alteración, pues solo se trata de ceros y unos; lo único que las puede diferenciar son los metadatos ${ }^{8}$ de cada fotografía, lo que permite que la fotografía en apariencia sigua siendo la misma, como un clon y pueda ser multiplicada hasta el infinito.

\section{Modelar y controlar}

No solo hay que tomar en cuenta que la fotografía es uno de los medios de difusión de más fácil reproducción gracias a su código binario digital, sino que también es una forma de modelar y controlar lo que aparece en el atlas cibernético, ya que se puede alimentar el mapa virtual nuevo equivalente al existente, dando como resultado una serie de dimensiones virtuales que se construyen a través de la fotografía modelando y controlando el mapa.

Modelar una cosa o algo más a través de una fotografía es una forma de control; establece un marco de transformación que altera lo visual, que le permite ser el resultado de una transformación de las cosas de tres dimensiones a dos dimensiones, la aplana y la traduce, no solo a un gráfico simbólico, sino a una representación ontológica de la cosa; al mismo tiempo la convierte a un código binario dispuesto a reproducirse y modelarse ilimitadamente.

El modelar y controlar el mundo de lo físico a través de la fotografía se ha vuelto una forma de ver y al mismo tiempo de observar algo, como un ejercicio recreativo casi automático de la mirada; ver ahora es sinónimo de cámara fotográfica, de fotografía. Ver ahora implica al sensor, a la pantalla y a nuestra muy personal forma de alterar el resultado de lo que vemos a través de los filtros, recortes, adiciones de texto y más.

"La manera de fotografiar una escultura o una pintura depende de quién sea el que está detrás del aparato." (Freund, 2001, p. 87). Como factores, modelar y controlar son una manera de llevar a cabo la idealización del hacedor de fotos y de participar en el atlas cibernético para proponer su ángulo de visión de la cosa. El

8 Los metadatos de una fotografía digital principalmente son: la fecha, la hora, la ubicación, los datos técnicos de la cámara, perfil de usuario, entre otros. idealizar es lo subjetivo del hacedor, es lo que le faculta para realizar la coerción sobre la cosa y el algo para proponer una representación bidimensional gráfica, la foto. "En ese sentido, al reorganizar los objetos dentro de sus imágenes, rehacen nuestra comprensión del mundo y hacen una contribución a nuestra descripción de él (PCM, p. 14). En otras palabras, la fotografía hace posible tener una nueva comprensión de nuestro entorno al resaltar nuevos elementos, al relacionar propiedades a un objeto que antes creíamos que no le correspondían." (Arias y de la Peña, 2008, p. 41).

Idealizar a través de la fotografía permite que se detonen pensamientos de consumo de las cosas; es un modo de disipar el mundo tangible, una alternativa de alteración de la materia física al estar haciendo y recopilando fotografías, las que se convierten en fetiche de acopio de personas, cosas o ideas que permiten reunir nuestros pensamientos, para convertirlos en una forma digital plástica y apilarlos; son colecciones gráficas que favorecen la evocación de esas idealizaciones.

Al lector empírico de las fotografías, las idealizaciones que contienen las imágenes también lo controlan, lo modelan. Si cada fotografía es realizada por un hacedor de fotos y tiene un ángulo de vista idealizado por él, esa visión se inscribe en la foto para que después sea vista por el público, sea compartida; al momento en que el lector empírico la ve, tiende a adoptar esa idealización inscrita por el hacedor. Por su parte el hacedor de fotos ya ha sido idealizado con otra serie de imágenes a las que se ha expuesto; de modo que el realizar fotografías se erige en un proceso de reciclaje de idealizaciones con leves mutaciones cada vez que un hacedor realiza una foto nueva de su objetivo.

Ver es una manera de modelar y controlar, es una de las facultades distintivas del ser humano, un sentido a través del cual delimita, interpreta y comprende su espacio. Desde los egipcios y babilonios, en su observación y contemplación de las estrellas y posición del sol para utilizarlo en la agricultura (King 1955, p. 1), la vista ya estaba ahí, al igual que en la cacería, la creación de herramientas, armas, entre otros. Existe evidencia física de un instrumento parecido al monóculo o telescopio (como hoy lo conocemos) que data del 3000 a.C. en Egipto (King, 1955, p. 2).

Una de las primeras modificaciones a la vista fue el lente y los diversos aumentos empleados para poder leer. El registro más antiguo data del siglo I d.C. y es de Séneca, tutor del emperador en Roma, quien en uno 


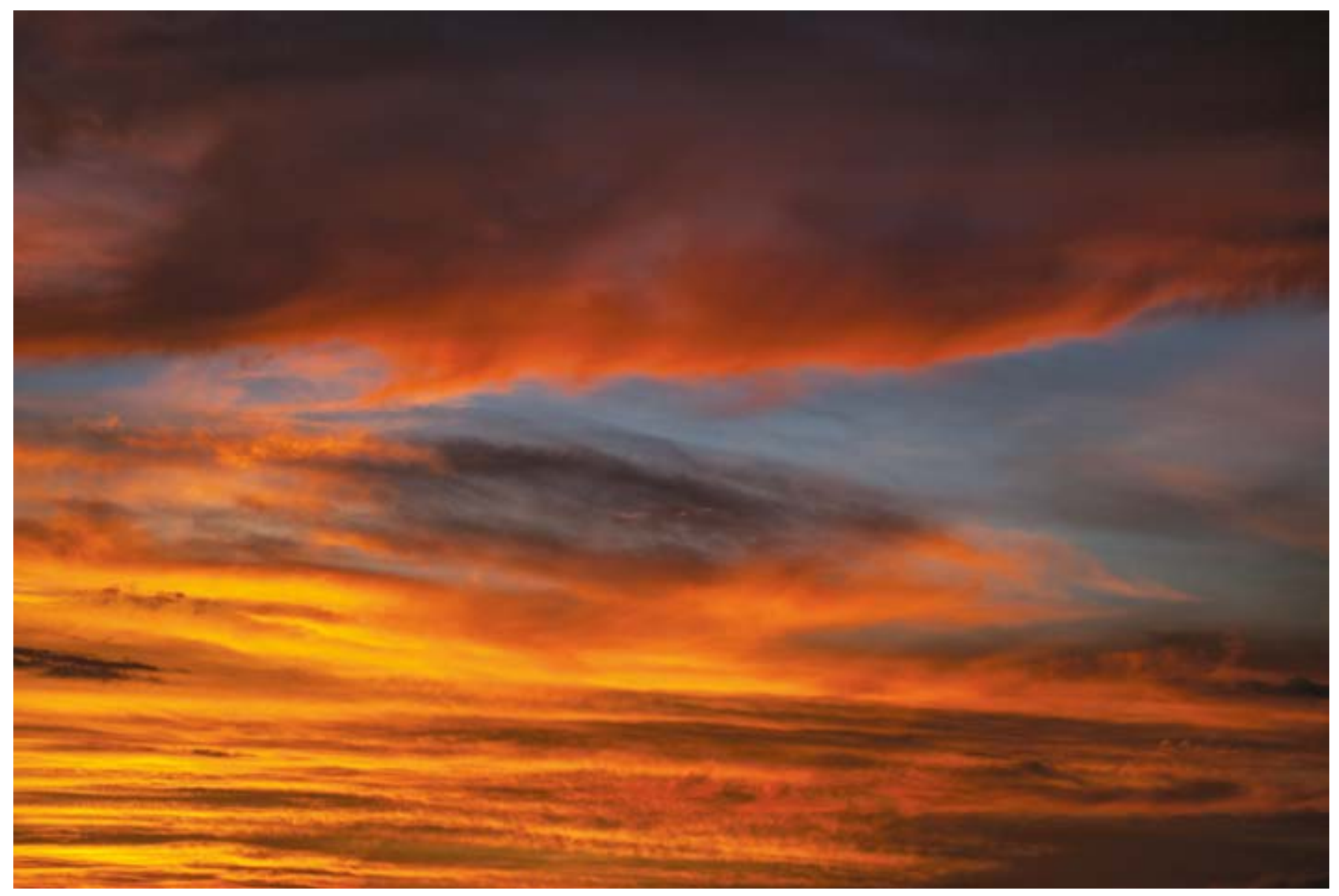

Imagen 4. 12/12/13. Sandra Rengifo. De la serie: Pil På Himlen (Flecha en el cielo). 2012 -2015. Fotografía Digital.

de sus escritos da cuenta de lo siguiente: "Letras, sin embargo pequeñas y borrosas, son vistas más amplia y claramente a través de un globo o vaso lleno de agua" (Kriss y Kriss, 1998, p. 902). Este tipo de modificaciones se dieron en un principio para regular las deficiencias de la vista, fueron una forma de corregirla, pero al mismo tiempo para extenderla, modelarla y controlarla.

Un salto en el tiempo nos lleva a una evolución de la manera de ver. Zacharias Janssen, en el siglo XVI, inventa el microscopio. Pasamos de observar las estrellas a observar los microrganismos, lo que implica una modificación radical al modo de ver, una forma nueva de realizar un escudriño a un mundo que no habíamos visto y que gracias a la ciencia y la tecnología se volvió visible. Al amplificar nuestra mirada comenzó a descubrirse una dimensión de la realidad completamente nueva.

Un siglo después Lippershey desarrolla el primer telescopio. Galileo, en el año de 1609 continúa desarrollando ese invento; con ayuda de un colega que fabricaba lentes, crea un telescopio con varios lentes que le permiten un mayor acercamiento a los objetos.
Esta nueva forma protésica de la vista, proporciona a nuestra mirada un aumento (zoom) de ella, que se convierte en el medio para alcanzar aquello que no habíamos podído observar-contemplar. Este hecho confirma que nuestra mirada establece nuestro lugar en el mundo, como lo apunta Berger (1972).

"La vista llega antes que las palabras. El niño mira e identifica antes de hablar" (Berger, 1972). Desde el principio de los tiempos hemos utilizado la vista como elemento principal para conducir las acciones humanas y darle significado a las cosas, lo que permite que les asignemos una apariencia, un color, una dimensión, un volumen y una serie de características que nos ayudan a clasificarlas, identificarlas y saber en qué posición estamos con referencia a ellas.

La vista es uno de los sentidos básicos y uno de los más desarrollados socialmente. Ver implica el manejo práctico de las dimensiones del espacio. Nuestra visión no permite una modificación del espacio, pero verlo a través de la cámara nos da la posibilidad de alterar lo visto; se puede contraer o expandir, reducir dimensiones 0 


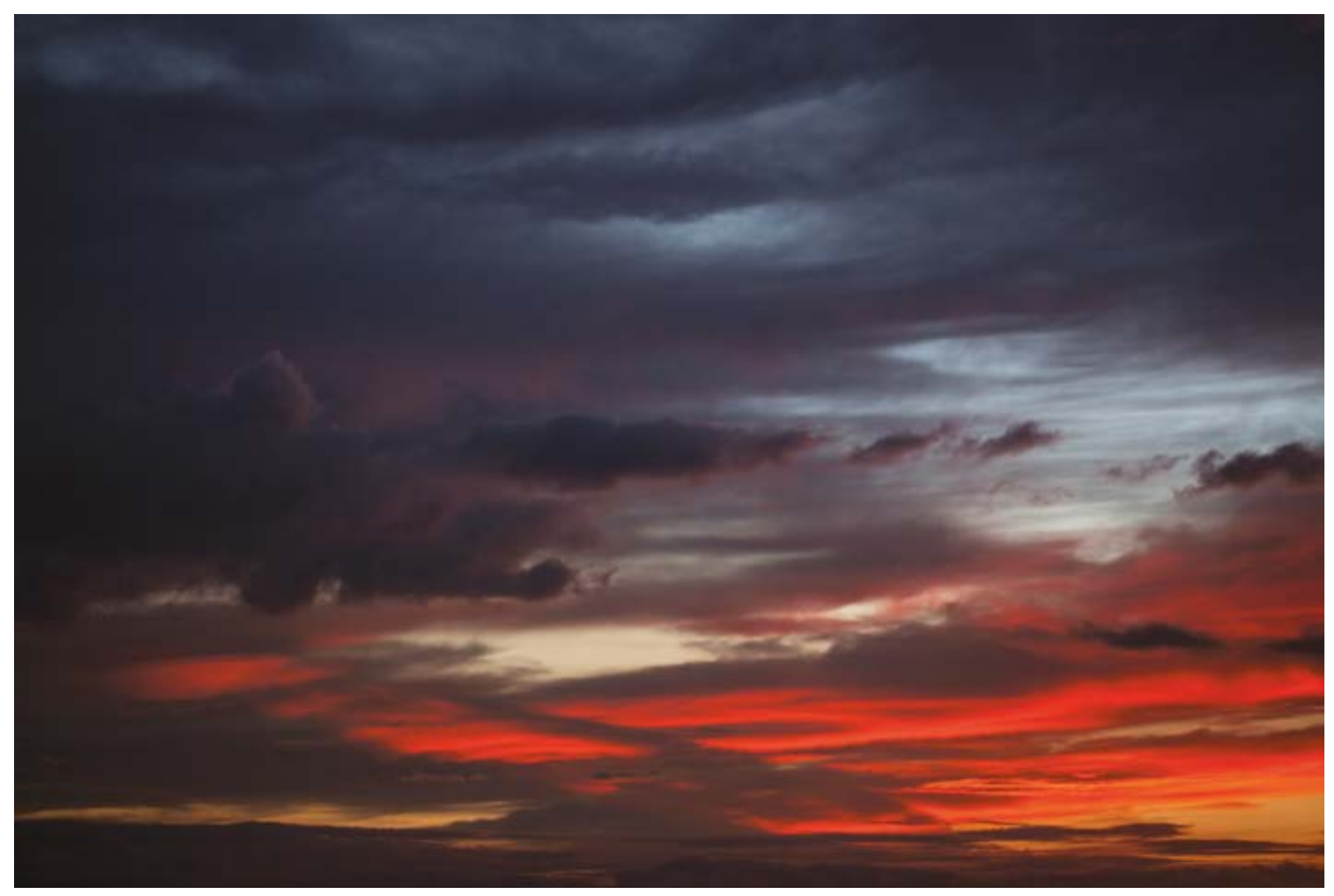

Imagen 5. 06/09/13. Sandra Rengifo. De la serie: Pil På Himlen (Flecha en el cielo). 2012 -2015. Fotografía Digital.

ampliarlas, hacerlo mono o policromático, así como una cantidad prácticamente infinita de conversiones.

\section{Conclusiones}

Entender el fenómeno de la fotografía requiere de nuevos pensamientos y de la evolución de los paradigmas epistemológicos, que ahora deberán ajustarse y modificarse a una nueva manera de discernir a la fotografía como dispositivo.

Algunos han llamado a esta nueva era fotográfica la "versión 2.0" y probablemente sea lo más adecuado, ya que la imagen fotográfica evoluciona más rápido de lo que los teóricos pueden racionalizar sus intereses, efectos y consecuencias. Considerando lo anterior, habrá que designar a la fotografía analógica como la versión 1.0, la digital como 2.0; pero las capacidades de inserción de la cámara para colocarse en otros aparatos que ahora "logran ver", es un fenómeno distinto al cual debemos enfocarnos.
Pensar en los efectos que producen los aparatos gadgets que tienen tres lentes para lograr diferentes formas de ver, "distintos efectos" en los resultados fotográficos, es una razón añadida a esta causa; además pone en perspectiva el tema de vigilancia, o lo que Bauman Ilama Vigilancia Liquida (2014). Muy pertinente pensar en ello, debido a que en la actualidad la mayoría de los aparatos integran una cámara que relativamente está activa en todo momento y que permite una gran penetración por parte del dispositivo fotografía y sus operadores en la civilización actual y en cada individuo en lo particular. Los mismos operadores (hacedores de fotos) influyen sobre otros hacedores, favoreciendo que estemos expuestos en todo momento a sus técnicas de dominación, entre otras incidencias culturales.

Es apremiante, como argumenta William John Thomas, preguntarnos ¿qué quieren las imágenes de nosotros y nosotros qué esperamos de ellas? (Mitchell), así como analizar y conocer qué tipo de poder les asignamos para afectar las emociones y el comportamiento humano. La respuesta nos llevará a promover la mesura en su uso y aplicación y posiblemente a una 
mejor utilización de las representaciones visuales que tengamos y creamos. Por supuesto que no se trata de invalidar o prohibir su uso, sino solo de evidenciar las diversas dimensiones de la fotografía que se encuentran implicadas y cuáles son sus costos y riesgos.

Por último, pero no como final de esta reflexión que invita y motiva a seguir discerniendo el fenómeno del dispositivo fotografía, sería recalcar que la intención que se le da a la fotografía desde su creación, es la de atrapar, secuestrar los pensamientos y las interpretaciones de los lectores. Ha sido hecha para eso, para ser conveniente, persuasiva, aspirar a ser axiomática. La imagen es un discurso en sí misma y no se puede pretender que para entenderlo baste con una sola mirada, pues ha sido claro que la mayoría de sus lectores son ingenuos a los intereses que la foto carga en su mensaje. El discurso en la fotografía es un filtro que permite ver sólo aquello que hemos seleccionado, discriminando al resto y evidenciando que lo que se ha grabado en la imagen es lo relevante, la prioridad ante todo lo demás que está a su alrededor.

\section{Referencias}

Agamben, G. (2006). ¿Qué es un dispositivo? Barcelona: Anagrama.

Arias, D. L. y de la Peña, I. (2008). Etica, poética y prosaica: ensayos sobre fotografía documental. Siglo XXI. Recuperado a partir de https://play.google.com/ store/books/details?id=1BFMUtqHR8IC

Baudrillard, J. (1981). El sistema de los objetos. (F. G. Aramburu, Ed.). Siglo XXI. Recuperado a partir de https://www.megaepub.org/book/jean-baudrillardel-sistema-de-los-ob.html

Bauman, Z. (2014). Vigilancia líquida. Expresso Zahar. Recuperado a partir de https://www.epubgratis.org/ vigilancia-liquida-zygmunt-bauman/

Bazin, A. (1976). ¿Qué es el cine? (Minicaja, v 1.0, Ed.), Qu'est-ce que le cinéma? Espa Book. Recuperado a partir de http://www.espaebook.com/book/ que-es-el-cine/

Belting, H. (2007). Antropología de la imagen. Buenos Aires: Katz.
Berger, J. (1972). Modos de Ver. Barcelona, España: Editorial Gustavo Gili. Recuperado a partir de https://itunes.apple.com/mx/book/modos-de-ver/ id1075790501? mt=11

Berger, J. (2013). Para entender la fotografía. Editorial Gustavo Gili. Recuperado a partir de https://itunes. apple.com/mx/book/para-entender-la-fotografía/ id1058812529?mt=11

Berger, J., Mohr, J. y Philibert, N. (2007). Otra manera de contar. Editorial Gustavo Gili. Recuperado a partir de https://itunes.apple.com/mx/book/ otra-manera-de-contar/id651977200?mt=11

Caivano, J. L. (1999). La representación del mundo visual en la fotografía y post-fotografía. Visio, 4(1), 153.

Costa, I. P. (2007). El coleccionista y su tesoro: la colección. Asociación Española de Dirección y Economía de la Empresa (AEDEM).

Dahó, M. (2015). Fotografías en cuanto espacio público. Revista de Estudios Globales y Arte Contemporáneo, 3.

Davis, F. (1975). La comunicación no verbal. (L. Mourglier, Ed.). Alianza. Recuperado a partir de http:// bajaepub.com/book/el-lenguaje-de-los-gestos-2603/

Derrida, J., Alarcón, J. M., y de Peretti, C. (1995). Espectros de Marx: el estado de la deuda, el trabajo del duelo y la nueva Internacional. Trotta. Recuperado a partir de https://books.google.com.mx/ books?id=ZUPIQgAACAAJ

Echevarren, J. M. (2010). Sociología visual: La construcción de la realidad a través de la imagen. (C. de E. Andaluces, Ed.). Universidad Pablo de Olavide.

Flusser, V. (2010). Hacia una filosfia de la fotografia. México D.F.: Editorial Trillas.

Fontcuberta, J. (2016). La furia de la imágenes. Galaxia Gutenberg. Recuperado a partir de https:// itunes.apple.com/mx/book/la-furia-de-las-imágenes/ id1157064717?mt=11

Freund, G. (1993). La fotografía como documento social. Barcelona, España: Editorial Gustavo Gili.

Gubern, R. (1996). Del bisonte a la realidad virtual. Anagrama. Recuperado a partir de http://www. 
megaepub.com/roman-gubern-del-bisonte-a-la-rea.

html

Heiferman, M. (2012). Photography Changes Everything. Smithsonian Institution.

King, H. C. (1955). The History of the Telescope. Dover Publications. Recuperado a partir de https://books. google.com.mx/books?id=KAWwzHIDVksC

Kriss, T. C. y Kriss, V. M. (1998). History of the Operating Microscope: From Magnifying Glass to Microneurosurgery. Neurosurgery, 42(4), 899-907. http://doi.org/10.1097/00006123-199804000-00116

Morris, E. (2014). Believing Is Seeing: Observations on the Mysteries of Photography. Penguin Press. Recuperado a partir de https://books.google.com.mx/ books?id=7LcBDAAAQBAJ

Sedano, M. G. (2015). Una revisión del concepto de postfotografía. Imágenes contra el poder desde la red. Liño, 21(21), pp. 125-132.

Sontag, S. (2016). Sobre la fotografía. Penguin Random House Grupo Editorial España. Recuperado a partir de https://itunes.apple.com/mx/book/sobre-la-fotografía/ id527485360? $\mathrm{mt}=11$ 